\title{
Práticas de RSAE em usinas de cana-de-açúcar: caso de uma região tradicionalmente produtora
}

\section{CSER practices in sugarcane industry: a case of a traditionally producing region}

\author{
CAROLINA JULIANA LINDBERGH FARIAS \\ RODOLFO ARAÚJO DE MORAES FILHO \\ JOSÉ DE LIMA ALBUQUERQUE \\ ANA MARIA NAVAES DA SILVA \\ Universidade Federal Rural de Pernambuco - UFRPE
}

\section{RESUMO}

O presente estudo foi desenvolvido visando identificar a gestão práticada nas usinas de cana-de-açúcar e relacionando-as ao conceito de Responsabilidade Socioambiental Empresarial (RSAE). Utilizou-se como base teórica o tripé da sustentabilidade, Triple Bottom Line, que se funda no estudo dos aspectos econômicos, sociais e ambientais. Pesquisa de natureza descritiva do tipo quali-quantitativa. Adotado como metodologia de abordagem o estudo de casos múltiplos realizado em um universo de treze usinas em operação na região escolhida (PE). Para coleta de dados utilizou-se entrevistas semi-diretivas e questionários em escala Likert, envolvendo gestores das usinas, dirigentes de sindicatos, associações e agentes de órgãos de fiscalização ambiental. Foram utilizadas para interpretação dos dados, técnicas de análise de conteúdo, estatística descritiva (teste de hipóteses) e análise multivariada de dados (análise de cluster). Observou-se que a gestão praticada pelas usinas converge para a existência de dois grupos: um formado por empresas que desempenham com responsabilidade socioambiental e outro formado por usinas menos adeptas às práticas sustentáveis. A constatação que se pode extrair permite concluir que a RSAE até existe na prática das usinas do setor, mas não advém da expectativa em obter 
vantagem competitiva e sim, como estratégia de sobrevivência. Palavras-chave: Responsabilidade Socioambiental. Sustentabilidade. Triple Bottom Line. Setor Canavieiro.

\section{Abstract}

The present study was developed to identify management practices in the sugarcane by relating to the concept of Corporate Social-Environmental Responsibility (CSER). The tripod of sustainability (Triple Bottom Line), which is based on the study of economic, social and environmental aspects of management, was used as a theoretical basis. Quali-quantitative and descriptive research. Study of multiple cases was used as methodology. The study area was a traditionally producing sugarcane region of the state of Pernambuco consisting of 13 plants in operation. The data collection was carried out through semi-directive interviews, and questionnaires were used on a Likert scale to be answered by the managers of the plants, union leaders and professionals responsible for monitoring environmental issues. Content analysis techniques were used and the statistical methods multivariate analysis. The management practiced converges to the existence of two groups: one formed by companies that play with greater socio-environmental responsibility and the other formed by plants less adept to sustainable practices. The conclusion from the research confirm that the CSER exists in the managerial practice of the plants of the sector, but that its inspiration does not properly come from an expectation to obtain competitive advantage; but as a survival strategy.

Keywords: Socio and environmental Responsibility. Sustainability. Triple Bottom Line. Sugar and alcohol industry.

\section{INTRODUÇÃo}

A principal atividade agrícola do estado de Pernambuco encontra-se historicamente fundada no plantio da cana-de-açúcar, desenvolvida na zona da mata há quase cinco séculos. Hoje, a produção de cana-de-açúcar nesse estado representa $26 \%$ da produção no Nordeste. Correspondendo o Nordeste a 4,56\% da produção de cana do Brasil. Juntos, os estados de Alagoas e Pernambuco perfazem um total de $53 \%$ da produção nordestina, segunda região mais importante em termos de produção de cana-de-açúcar no país (MAPA, 2016/17). 
Atuando nesse contexto dentro de um enfoque sistêmico, as usinas apresentam um grande potencial para aumentar a produtividade, operando de formas a utilizar seus resíduos com geração de novas energias, além de beneficiar a natureza com a diminuição do impacto negativo sobre o meio ambiente. Medidas mitigadoras de todas essas questões têm sido divulgadas pelos órgãos técnicos (Embrapa, em especial) no sentido de ajudar na minimização de todos esses problemas.

Do ponto de vista social sabe-se que o cultivo da cana-de-açúcar cresceu através de péssimas condições de trabalho, caracterizado por trabalho escravo, informal, trabalho infantil, com péssimas condições de renda e subsistência. O cultivo da cana-de-açúcar demandava grande número de trabalhadores e foi responsável pelo surgimento de pequenas cidades nas redondezas voltadas para o atendimento das necessidades do grande número de pessoas que se conglomeravam ao redor da indústria canavieira.

Ao longo do contexto histórico da atividade canavieira, não se observa aspectos de envolvimento da gestão das usinas com o social e ambiental que motivassem discussões sobre a inserção dos mesmos na gestão do setor (GOMES, 2011).

Essa situação de descaso para com o social fez surgir na década de 60 em Pernambuco, o movimento das ligas camponesas, movimento reivindicatório de direitos básicos não atendidos. Elas foram substituídas com o passar dos tempos pelas organizações sindicais e associações rurais que passaram com maior eficácia a fiscalizar as leis de responsabilidade social nas usinas de cana de açúcar, e as leis de proteção ambiental que ocasionaram diversas transformações na gestão administrativa das usinas, até a chegada do contexto atual.

A questão ambiental era também tratada sistematicamente de forma deficiente. Um exemplo eram os constantes despejos do subproduto vinhaça (tiborna) sem nenhum tratamento no leito dos rios, causando enorme mortandade de peixes. Poluindo o ambiente com um odor insuportável além de contribuir para a degradação dos mananciais aquíferos. Tudo isso se fazia sem nenhuma consequência regulatória de ordem ambiental.

A presente pesquisa visa identificar como está sendo realizada a atual gestão nas usinas de cana-de-açúcar com o propósito 
de saber se os atuais gestores buscaram se adequar às normativas legais e também se criaram consciência sobre as antigas práticas ambientais exercidas no setor que não podem mais ser encontradas. Outra questão de interesse que deriva dessa preocupação é a de se intentar compreender quais fatores podem melhor explicar uma maior identidade das empresas para com a adoção de práticas de gestão sustentáveis: Nível de consciência de seus gestores? Busca em adquirir vantagem competitiva? Pressão dos stakholders para cumprimento das normativas legais? Melhorias na imagem da firma?

A teoria, costuma tratar esses temas de forma separada a partir da visão de cada autor individualmente, não facultando assim a abordagem dessas questões de uma maneira conjunta. A ausência de respostas que proporcione uma visão integrada, levando em conta as características socioculturais da região onde as empresas atuam e seus estilos de gestão, para explicar as motivações de uma maior ou menor intensidade na adoção de práticas sustentáveis, constitui em nosso entendimento uma lacuna, e que motivou a presente pesquisa.

No caso em epígrafe, é presumível que a gestão tenha melhorado com a chegada à direção dos filhos e netos dos antigos senhores de engenho (usineiros). Mas até que ponto? Percebe-se também que muitas empresas até hoje, não cuidam de maneira condizente da dimensão socioambiental em suas práticas de gestão. E por vezes nem mesmo da questão empresarial, dado que o parque industrial tem sofrido pesadas perdas com o fechamento de usinas na região, muito embora a produção de cana-de-açúcar em toneladas venha se mantendo. As usinas parecem encerrar suas atividades industriais passando a se tornar fornecedoras de matéria-prima (fornecedores de cana) para a moagem de outras empresas na mesma região.

Considerando assim a importância da atividade para a economia da região, somada à questão social e ambiental atreladas ao segmento, surge assim a questão-problema a ser respondida pela pesquisa: De que forma a gestão empresarial é praticada nas usinas de cana-de-açúcar de uma região tradicionalmente produtora?

Ao responder esse questionamento será possível verificar se a gestão empresarial desenvolvida por essas usinas está sendo praticada dentro dos preceitos da RSAE (Responsabilidade Socioambiental 
Empresarial) ou próxima dela. Afastando-se definitivamente das práticas perpetradas pelos antigos "coronéis do açúcar".

O estudo utiliza como base teórica para essa verificação, o tripé da sustentabilidade empresarial que segundo Elkington, J. (2004) reflete nos aspectos econômicos, sociais e ambientais permitindo averiguar do ponto de vista analítico, como vem se desempenhando a atividade empresarial no setor, o chamado: Triple Bottom Line (TBL). Para cumprimento dessa perspectiva, o presente ensaio encontra-se estruturado em cinco (5) partes, incluindo essa introdução, seguindo-se: referencial teórico, metodologia, análise de resultados, e considerações finais.

\section{RESPONSABILIDADE SOCIOAMBIENTAL CORPORATIVA}

O conceito de responsabilidade socioambiental corporativa surgiu a partir da década de 80 , como uma junção da responsabilidade nas esferas social e ambiental, inserindo o conceito nas corporações, governos, na tentativa de equilibrar as ações de forma economicamente viável e sustentável.

\subsection{Sustentabilidade empresarial}

Em 1994, o movimento de responsabilidade socioambiental empresarial começou a ter visibilidade e reconhecimento. Assim, em 1995, a associação da Câmara do Comércio Internacional (ICC) se junta com o Conselho Empresarial para o Desenvolvimento Sustentável (BCSD), formando o primeiro órgão internacional com ações voltadas para o desenvolvimento sustentável, chamado World Business Council for Sustainable Development (CMMAD, 1988). Na concepção desse Conselho, Responsabilidade Social Corporativa (RSC) é o compromisso contínuo por parte das empresas para contribuir com o desenvolvimento econômico enquanto melhora a qualidade de vida dos trabalhadores e seus familiares, bem como a comunidade e a sociedade em geral (WORLD BUSINESS COUNCIL, 2002, p.3).

Com o tempo, os gestores perceberam que o apelo ao conceito de responsabilidade socioambiental empresarial (RSC) junto à mídia, ao governo e a sociedade, traziam benefícios para as empresas. No início era muito comum a empresa estabelecer grande marketing na 
questão social. Em contrapartida, causavam enormes danos ao meio ambiente, sendo valorizada pelas ações sociais que desenvolviam.

Passam a existir assim várias críticas à responsabilidade social, defendendo que as empresas a utilizava como fachada e escondiam suas ações ambientais completamente irresponsáveis (MELO NETO e FROES, 2010).

Banerjee (2007) engrossando essas críticas definiu a RSC praticada pelas empresas como sendo um conjunto de ações pautadas por uma lógica meramente instrumental, a qual visa legitimar pelo social, os seus significativos ganhos financeiros.

Com o aumento dos problemas ambientais muitas empresas foram obrigadas a focar em ações ambientais, o que em consequência contribuiu para a diminuição de suas ações sociais.

Com o tempo, a alternativa encontrada foi a de juntar os focos: social, ambiental, e também o econômico, ampliando o conceito para formar os contornos da sustentabilidade empresarial.

Nesse sentido segundo Balbino et al. (2015) torna-se necessário que as empresas se insiram nessa nova realidade, tentando reconhecer as carências de cada grupo, para que tenham condições de planejar ações mais significativas contribuindo assim para o bem-estar social, a dimensão econômica da empresa e a preservação ambiental.

O conceito de sustentabilidade empresarial se inseriu no planejamento estratégico das organizações como estratégia de posicionamento da empresa no setor onde atua, fazendo com que a perspectiva de responsabilidade socioambiental surgisse como uma alternativa para a sobrevivência e progresso das organizações em longo prazo (AAKER, D. et al., 2012.; OLIVEIRA, D. R. 2014.; MINTZBERG, H. et al., 2010.; NASCIMENTO, LEMOS, e MELLO, 2008).

Nesse contexto as empresas se viram obrigadas a rever suas estratégias, tecnologias e produtos, com base nas dimensões da responsabilidade socioambiental, se tornando um desafio para as empresas à prática do conceito, pressionadas pelos stakeholders (MELO NETO e FROES, 2011).

A empresa que buscasse atender às questões sociais e ambientais de forma ainda a gerar lucro começou a ser vista como possuidora de uma gestão sustentável, a qual passou a integrar o planejamento estratégico das organizações. Essa atuação vem sendo 
utilizada como instrumento de agregação de valor à marca da empresa, definindo seu posicionando no mercado como uma empresa comprometida com as gerações futuras (BARBIERI, 2011).

Cada vez mais influenciada pelas representações da sociedade, as organizações também formam e transformam as representações sociais, levando com seus valores a provocar mudanças na forma de pensar e agir das pessoas (CARROLL, 1991).

Essas mudanças nas esferas empresarial e governamental, parte do interesse do consumidor por produtos e serviços decorrentes de práticas economicamente viáveis, socialmente justas e ambientalmente corretas, que leva a estratégia da organização ser desenvolvida com foco na sustentabilidade, tendência que vem ganhando força de maneira irreversível na sociedade contemporânea (SEBRAE, 2012).

De acordo com a definição de RSC do Instituto Ethos (2016) essa é uma forma de gestão que estabelece uma relação ética com todos os públicos com os quais a empresa está interligada (stakeholders) impulsionando o desenvolvimento sustentável de forma holística de sorte a preservar recursos ambientais para as gerações futuras e assumindo papel proativo com a redução das desigualdades sociais. Muito embora esses conceitos não venham sendo percebidos ainda por uma parcela significativa de gestores de empresas.

A aplicação do conceito de RSC em uma empresa, implica no desenvolvimento de uma administração caracterizada por uma mudança nos valores da cultura empresarial tradicional, evoluindo do paradigma de dominação para a parceria, da ideologia do crescimento econômico para a ideologia da sustentabilidade ecológica. Implica mudança do pensamento mecanicista para o pensamento sistêmico holístico. Tal postura passa a exigir de acordo com Tachizawa, (2011): "um gestor com consciência ecológica e socialmente responsável por excelência".

Segundo Coral (2002) o tratamento de questões sociais e ambientais devem ser observadas como tendências que podem trazer para a empresa uma vantagem competitiva, através da identificação de novas oportunidades de negócios e ajudando a empresa a adquirir uma postura proativa.

$\mathrm{Na}$ questão ambiental a sociedade pressiona as empresas para incorporarem valores como um ambiente mais limpo em seus procedimentos operacionais (SANCHES, 2000). 
Bowie e Dunfee, (2002 apud. Haigh e Jones, 2006) relacionam os estudos da responsabilidade socioambiental empresarial enfatizando a necessidade de superar conflitos entre os motivos éticos e o lucro, considerando as contradições inerentes entre a busca do crescimento econômico com os objetivos da manutenção ecológica e justiça social.

Portanto, para uma empresa se tornar social, econômica e ambientalmente responsável, deve caracterizar-se pela grande ênfase que atribui às questões sociais e ambientais de forma explícita, e econômica de forma implícita em seus processos de gestão, de forma que a sobrevivência econômico-financeira seja condicionada ao comportamento responsável (MELO NETO; FROES, 2011; MATTIOLI; CASTRO; CLARO; VIEIRA; SPERS, 2015).

Segundo Bueno et al. (2011), as ações desenvolvidas pela empresa com ênfase nas esferas social, ambiental e econômica podem ser consideradas uma busca pela sustentabilidade empresarial.

Para Zylbersztain e Lins (2010, p. 40), a "sustentabilidade empresarial pode ser compreendida como a busca pela excelência de gestão, desafiando as empresas a serem economicamente viáveis, ambientalmente corretas, e socialmente justas".

Essa alteração na perspectiva, faz com que a mudança na estrutura organizacional se preocupe em desfazer-se de práticas consideradas irresponsáveis ou mesmo, ultrapassadas, caracterizadas por uma antiga gestão e busque estabelecer uma postura comprometida com as atividades desenvolvidas na empresa no aspecto social e ambiental.

É de conhecimento geral que o público consumidor, cada vez mais exigente quanto à atuação das empresas no meio ambiente, quando um empreendimento, buscando entrar em conformidade com os requisitos ambientais decide adquirir um selo ecológico, a empresa acaba se destacando perante a concorrência. Assumindo sua responsabilidade social, essa atitude torna-se um diferencial no mercado fortalecendo e agregando valores à marca (IBDN, 2017).

Hoje em dia, os clientes estão cada vez mais informados e predispostos a comprar e usar produtos que respeitem o meio ambiente. O produto ecologicamente correto vende mais nos mercados e detém a preferência do consumidor justificando para a empresa a busca por selos de sustentabilidade. 
A Bolsa de Valores de São Paulo, diante do crescente interesse dos investidores em migrar para os portfólios verdes, organizou para as empresas um índice de responsabilidade social e sustentabilidade (Índice de Sustentabilidade Empresarial - ISE) a exemplo do índice da Bolsa de Valores de Nova York (Dow Jones Sustainability Indexes - DJSI) (TACHIZAWA, T.; ANDRADE, R., 2011, p. 4).

Esses índices têm o propósito de monitorar e informar aos investidores, o desempenho financeiro das empresas que têm seu negócio orientado pela referência da sustentabilidade, criando assim as condições para tornar o conceito de responsabilidade socioambiental empresarial (RSAE) um negócio lucrativo.

O Triple Bottom Line (TBL), modelo de sustentabilidade empresarial que engloba as três dimensões (econômica, ambiental e social), também chamado de tripé da sustentabilidade, e que foi apresentado em 1987 por John Elkington, corresponde à preocupação que as organizações devem ter para com as pessoas, com o negócio, o lucro que garante a atividade e a preocupação com o meio ambiente (NEVES e CONEJERO, 2010).

O TBL aborda os resultados da empresa não apenas pelo valor econômico adicionado, mas também pelo valor social e ambiental que elas criam - ou destroem. A sustentabilidade é analisada a partir das dimensões TBL conforme apresentada na figura 1. O modelo TBL é também conhecido como 3Ps da sustentabilidade: people (pessoas), profit (lucro), planet (planeta).

\section{Figura 1- Triple Bottom Line}

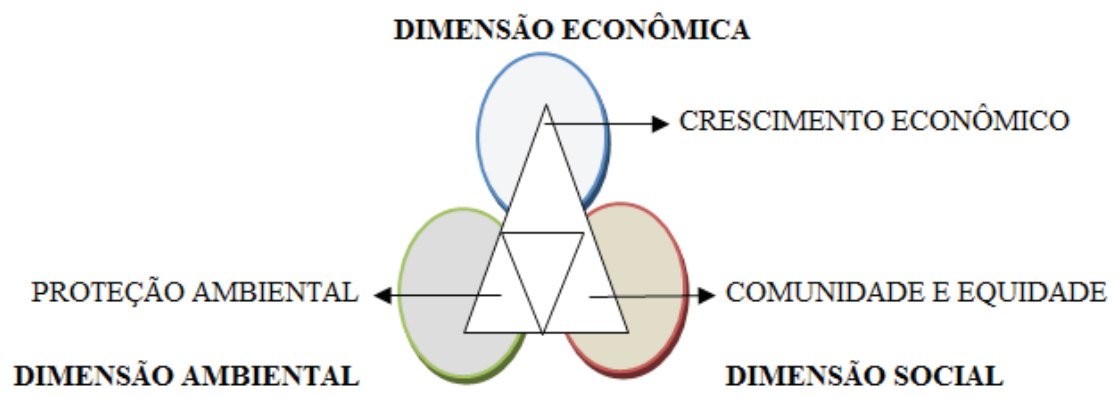

Fonte: Elaboração própria adaptado de Elklington (2004) 
Pope et al. (2004), analisam os três pilares para a avaliação da sustentabilidade a partir das dimensões apontadas por Elklington (1987), porém considera os impactos ambientais o cerne das preocupações da sustentabilidade. Seu esquema é apresentado por três círculos concêntricos, o externo representando a ecologia, no meio a representação da sociedade e o do interior representando a economia.

Na dimensão econômica destaca-se o crescimento, a eficiência e a estabilidade dos recursos e condições financeiras como importantes meios para a busca da sustentabilidade (MUNASINGHE, 2010). Essa dimensão busca reduzir os custos sociais e ambientais. O lucro que garante a continuidade do investimento pela atratividade do ramo na indústria (NEVES, 2007).

A dimensão ambiental se preocupa com a capacidade do ambiente natural voltar ao seu equilíbrio após sofrer alguma intervenção. É uma preocupação constante, que se refere aos impactos da organização sobre o meio natural. Segundo Sachs (2000) essa dimensão deve considerar os recursos naturais que são renováveis e limitar o uso dos recursos não renováveis.

Na dimensão social, busca-se equilibrar a renda, garantir as oportunidades de participação com vistas à redução das desigualdades entre os atores envolvidos.

Haigh e Jones (2006) identificaram em seus estudos seis conjuntos de influências que podem promover ações de responsabilidade social dentro da empresa: pressões internas sobre os gerentes de negócio, pressões de concorrentes de negócios, investidores e consumidores, e pressões regulatórias que vêm de governos e organizações não governamentais.

Rabello e Silva (2011) sintetizam algumas possibilidades de análise de indicadores de Responsabilidade Social cujos enfoques vão desde o TBL (Triple Bottom Line) aos Indicadores Ethos, considerando sete dimensões da sustentabilidade, a saber, transparência, meio ambiente, público interno, governo e sociedade, fornecedores, clientes e consumidores, considerando o relacionamento com seus stakeholders.

Pope et al. (2004) descreve que para melhor entender o desenvolvimento sustentável é importante fazer uma avaliação da sustentabilidade de forma integrada, onde as dimensões avaliadas 
não sejam consideradas isoladas e se relacionem de forma dinâmica onde possam formar uma sinergia maior do que a simples avaliação da soma de suas partes separadas.

Com efeito, além da relação integrada das dimensões da sustentabilidade, as abordagens contemporâneas consideram a avaliação dos impactos entre os três pilares de forma sinérgica na constituição de medidas para a sustentabilidade (POPE et al., 2004).

\subsection{Os impactos no meio ambiente da atividade de cultivo da cana-de-açúcar}

Voltando a discursão da RSAE para a cultura canavieira, visando um melhor entendimento relacionado às ações de responsabilidade social, ambiental e econômica no setor, descreve-se a seguir os principais impactos dessa atividade no meio onde atua.

Segundo Alcarde (2012) o processamento de uma tonelada de cana-de-açúcar resulta em diversos produtos e subprodutos entre eles o bagaço da cana, a torta de filtro, o melaço, a vinhaça, o álcool bruto, o açúcar, a levedura seca, entre outros. Estima-se que para cada tonelada de cana-de-açúcar processada, tem-se conforme a tabela (1) abaixo, os seguintes resultados dos produtos/subprodutos:

Tabela 1-Produtos do processamento de 1t de cana-de-açúcar

\begin{tabular}{|l|l|l|}
\hline Produto/Sub-produto & $\begin{array}{l}\text { Quantidade produzida por lt de cana-de } \\
\text { açúcar processada }\end{array}$ & Média \\
\hline Bagaço & $250 \mathrm{~kg}$ & $250 \mathrm{~kg}$ \\
\hline Torta de Filtro & Entre 20 a $40 \mathrm{~kg}$ & $30 \mathrm{~kg}$ \\
\hline Melaço ou mel final & Entre 40 a $60 \mathrm{~kg}$ & $50 \mathrm{~kg}$ \\
\hline Vinhaça & Entre 12 a 18 litros / (álcool) & 151 \\
\hline Álcool bruto & Entre 1 a 5 litros / 1001 (álcool) & 31 \\
\hline Levedura seca & $2,5 / 1001$ (álcool) & $2,5 \mathrm{~kg}$ \\
\hline
\end{tabular}

Fonte: Elaboração própria dados de ALCARDE (2012)

Dentre os principais impactos ambientais causados pelo processamento da cana-de-açúcar são aqui listados alguns, conforme se apresenta na sequência: a) Redução da biodiversidade em função do 
desmatamento na implantação da monocultura; b) Contaminação das águas superficiais e subterrâneas e do solo pelo excesso de adubos químicos, herbicidas e defensivos agrícolas; c) Compactação do solo pelo tráfego de máquinas pesadas durante o plantio diminuindo sua fertilidade; d) Assoreamento de cursos d'água pela erosão do solo em áreas de plantio; e) Emissão de fuligem e gases de efeito estufa pela queima da palha ao ar livre no período da colheita; f) Danos à fauna e à flora, provocados pela incidência de incêndios descontrolados; g) Concentração de terras, renda e, h) Condições precárias de trabalho que caracterizam todo regime de plantation (monocultura) (ALCARDE, EMBRAPA AGEITEC, 2012).

Dentre os impactos ambientais mais conhecidos, o da queima da palha (as queimadas) é o que tem maior apelo social. Assim, quanto ao problema das queimadas que tanto aflige as populações do entorno, recomenda-se realizar o plantio da cana, de sorte que a colheita coincida com o início das chuvas, pois ela tenderá a aumentar a possibilidade de sedimentação dos poluentes em suspensão. Igualmente, realizar a pulverização em momentos de alta umidade relativa e pouco vento. E priorizar o emprego de herbicidas rapidamente degradáveis para o controle químico de plantas daninhas. Essas são algumas medidas ambientais recomendadas como boas práticas de plantio.

A atividade canavieira, sendo considerada de muita importância para a economia do estado, a pesquisa visa levantar de que modo sua gestão vem sendo praticada no sentido de tornar suas ações cada vez mais sustentáveis.

\section{Percurso metodológico}

Trata-se de uma pesquisa descritiva de natureza qualitativa, na busca de análise de dada realidade social (VIEIRA; RIVERA, 2012), embora também quantitativa (VERGARA, 2009). Segundo Roesch (2005), abordagens qualitativas e quantitativas podem contemplar variados tipos de projetos de pesquisa.

O objetivo da pesquisa foi verificar como a gestão empresarial desenvolvida nas usinas de cana de açúcar em Pernambuco está sendo praticada, se possuem (ou não) práticas com responsabilidade socioambiental empresarial trilhando novos caminhos através da geração de produtos inovadores oriundos dos resíduos da cana- 
-de-açúcar, contribuindo com a minimização de danos negativos ao meio ambiente, atendendo à legislação ambiental e trabalhista existente, proporcionando melhores condições sociais e minimizando os impactos ambientais.

A pesquisa foi realizada através de entrevistas semi-estruturadas, realizadas com os gestores de usinas de cana-de-açúcar, órgãos representativos de classes (Associações Sindicais e Sindicato Patronal), órgãos de fiscalização ambiental e trabalhista $(\mathrm{CPRH}$, DRT). Nessas instituições eram entrevistados o seu Diretor Geral ou substituto indicado.

Além das entrevistas semi-diretivas (baseadas em questões abertas) aplicou-se um questionário com intervalo de Likert aos gestores das usinas. A amostra abrangeu 08 usinas de um universo de 13 em funcionamento na região (em cinco não se conseguiu ter acesso) tendo-se entrevistado em cada unidade de dois a três gestores responsáveis. As variáveis investigadas tiveram como base os indicadores, conforme se apresenta no Quadro 1.

\section{Quadro 1 - Indicadores investigados na pesquisa}

\begin{tabular}{|l|l|}
\hline DIMENSÃO & VARIÁVEIS \\
\hline Ambiental & $\begin{array}{l}\text { Técnicas de conservação do solo; Preocupação com a emissão de } \\
\text { efluentes, Tratamento e aproveitamento de resíduos; Utilização de } \\
\text { energias renováveis; Política ambiental, Mecanismos de verificação da } \\
\text { política ambiental, Parcerias com entidades focadas no meio ambiente; } \\
\text { Respeito à biodiversidade, Preservação ambiental, Utilização de defen- } \\
\text { sivos agrícolas biodegradáveis, Uso de adubação orgânica; Cuidados } \\
\text { em queimadas. }\end{array}$ \\
\hline Social & $\begin{array}{l}\text { Clima e cultura organizacional; Participação da gestão em projetos } \\
\text { sociais voluntários, Assistência à saúde, Política de segurança no } \\
\text { trabalho, Responsabilidade social (pagamento dos salários em dia, } \\
\text { práticas trabalhistas, respeito aos direitos humanos); Treinamento e } \\
\text { capacitação, Diversidade e gênero (contratação de mulheres, deficien- } \\
\text { tes físicos). }\end{array}$ \\
\hline Econômica & $\begin{array}{l}\text { Estratégia empresarial; Qualidade dos produtos; Geração de novos } \\
\text { negócios sustentáveis; Recolhimento e aproveitamento de resíduos; } \\
\text { Relacionamento com o cliente no pós-venda, Nível de investimento e } \\
\text { exportação. }\end{array}$ \\
\hline
\end{tabular}

Fonte: Elaboração própria. 
A partir da seleção desses indicadores foi construído um questionário que se apresentou composto por 41 questões formuladas para identificar as práticas de gestão nas usinas, sendo 18 questões formuladas sobre a dimensão ambiental, 15 questões de cunho social e 08 questões de natureza econômica. $\mathrm{O}$ intuito, importante aqui reforçar, nunca deixou de ser, procurar se entender em que medidas essas práticas rebatiam com os preceitos da RSAE.

Além das entrevistas foram aplicados questionários utilizando-se o intervalo de Likert buscando mensurar a intensidade de cada variável na apuração das respostas.

A pesquisa de campo se deu no período de outubro de 2014 a maio de 2015.

Para a análise dos dados obtidos através do intervalo de Likert utilizou-se o cálculo do fator RM - Ranking Médio, para cada variável obtido como segue:

Cálculo do fator RM (Média): $R M=\Sigma($ fi $X \mathrm{Ri}) / \mathrm{N} ; \mathrm{RM}=$ Ranking Médio (ou Média); fi = Frequência observada de cada resposta para cada item; $\mathrm{Ri}=$ Conceito atribuído a cada assertiva (1-5); $\mathrm{N}=$ Quantidade de respondentes.

Quadro 2 - RM: faixas de interpretação

\begin{tabular}{|l|l|}
\hline Variação do RM & Interpretação \\
\hline $1,00-2,49$ & Intervalo de discordância \\
\hline $2,50-3,49$ & Zona de indiferença \\
\hline $3,50-5,00$ & Intervalo de concordância \\
\hline
\end{tabular}

Fonte: Adaptado de Vasconcelos, Y. (2014, p. 16)

Após analisar os dados sistematizados pelo modelo do ranking médio, enriquecida com a técnica de análise de conteúdo teorizada por Bardin (2011), verificou-se a necessidade em aplicar uma análise de cluster. Foi aplicada uma análise de cluster para separar de per si, grupos heterogêneos observados quando da análise dos dados qualitativos (CORRAR, L. J.; EDILSON, P.; DIAS FILHO, J. M. 2009.; PESTANA, M. H.; GAGEIRO, J. N., 2014). 
A análise de cluster é um processo de partição de uma população heterogênea em subgrupos mais homogêneos (DONI, 2004, p. 21). Foi também aplicado um teste entre duas médias com o fim de identificar sob que variáveis as práticas de gestão eram diferenciadas (MONJALLON, 1980).

\section{RESUltAdos DA PESQUiSA}

Com esse referencial, inicia-se a descrição das análises buscando-se compreender de que forma é praticada a gestão das usinas no setor em estudo, no intuito de identificar os principais aspectos e ainda, com que intensidade a RSAE (se existir) é praticada.

\subsection{Caracterização da amostra}

Foi planejada a visita às trezes (13) usinas em funcionamento na região, porém não foi possível como no início se desejava, uma vez que algumas unidades (05 usinas) por motivos diversos se recusaram em participar da pesquisa. Assim, obteve-se um quadro institucional formado pelas seguintes empresas (ver quadro 3).

Quadro 3 - Empresas contatadas no estudo (usinas em funcionamento /PE)

\begin{tabular}{|c|c|c|c|c|c|c|}
\hline Casos & Usinas & $\begin{array}{c}\text { Produtos } \\
\text { Comecializados }\end{array}$ & $\begin{array}{c}\text { Total de } \\
\text { Funcion. (Campo } \\
\text { e Ind. /Safra 2014) }\end{array}$ & $\begin{array}{l}\text { Certificados } \\
\text { Ambientais }\end{array}$ & $\begin{array}{c}\text { Processos } \\
\text { Ambientais } \\
\text { (últ. } 03 \text { anos) }\end{array}$ & $\begin{array}{c}\text { Processos } \\
\text { Trabalhistas } \\
\text { (últ. } 03 \text { anos) }\end{array}$ \\
\hline \multirow{2}{*}{1} & \multirow{2}{*}{ A } & Açúcar/Álcool & 4.500 & - & - & - \\
\hline & & Energia elétr/ $\mathrm{Co} 2$ & & & & \\
\hline \multirow{2}{*}{2} & \multirow{2}{*}{$\mathbf{B}$} & Áçúcar / & 2.000 & - & - & 1 \\
\hline & & Álcool & & & & \\
\hline \multirow{2}{*}{3} & \multirow{2}{*}{ C } & Álcool / Açúcar & 3.290 & ISO 9000 & - & 1 \\
\hline & & / Energia & & e 9001, Couche & & \\
\hline \multirow{2}{*}{4} & \multirow{2}{*}{ D } & Álcool/Açúcar & 4.500 & Prêmio Fiep & - & - \\
\hline & & / Energia & & & & \\
\hline \multirow{2}{*}{5} & \multirow{2}{*}{$\mathbf{E}$} & Açúcar / & 1.900 & & - & - \\
\hline & & Briquetes & & & & \\
\hline \multirow{2}{*}{6} & \multirow{2}{*}{$\mathbf{F}$} & Álcool / Açúcar & 5.600 & Prêmios & 1 & - \\
\hline & & Energia Elétrica & & ambientais & & \\
\hline \multirow{2}{*}{7} & \multirow{2}{*}{ G } & Álcool / Açúcar & 1.100 & ABRINC, & 1 & - \\
\hline & & Energia Térmica & & IPMA & & \\
\hline \multirow{2}{*}{8} & \multirow{2}{*}{$\mathbf{H}$} & Álcool / Açúcar & 3.500 & EPA, BPF, & 1 & - \\
\hline & & Energia/ Bagaço & & APPCC & & \\
\hline
\end{tabular}

Fonte: Dados da Pesquisa 


\subsection{Análise dos dados}

Os resultados a seguir apresentados, são uma síntese dos estudos realizados nas usinas de cana-de-açúcar do estado de Pernambuco onde se buscou entender como se dá a responsabilidade socioeconômica e ambiental do setor na região. Tem-se então endereçado o Quadro 4 que sintetiza as relações ligadas ao comportamento das usinas no que tange a aderência de suas práticas gerenciais aos princípios da RSAE.

\subsubsection{Aspectos da dimensão ambiental}

Tomando a dimensão ambiental aposta no quadro em análise (Quadro 4) observa-se que a maior parte das variáveis respondidas, tem como zona de concentração a área de concordância $(3,50$ - 5,00) dentro da escala de Likert, não obstante, recair pelo menos quatro medidas na área considerada de indiferença. A Variável 02 "Verificação da política ambiental” $(2,63)$ e a Variável 13 “Uso de adubo orgânico no canavial" $(3,38)$.

Vê-se ainda, a Variável 06 "Divulgação do desempenho ambiental" $(2,88)$, e a Variável 07 " $\mathrm{N}^{\circ}$ de aspectos ambientais divulgados" $(3,00)$ ambas recaindo também na zona de indiferença do modelo. Isso leva a intuir, pela natureza dessas medidas, que não há uma maior sensibilidade por parte das usinas da região, em divulgar de uma maneira sistemática as ações voltadas para o meio ambiente. Uma explicação seria que, tratando-se de uma comodity que é vendida nos mercados a qualquer tempo, parece que os proprietários não estão preocupados em passar uma imagem da fabricação de açúcar como uma "atividade verde", que de fato não é. Mas isso expressa uma desatenção para com a formação de uma "opinião pública favorável" quanto às ações de cunho ecológico por parte das usinas. Tampouco a formação de uma consciência crítica interna de seus colaboradores para com as questões ambientais.

Reconhece-se, no entanto, que em muitos aspectos da questão ambiental, a situação está bem melhor do que se podia verificar em tempos atrás. Onde não havia a menor preocupação com a preservação do meio ambiente, com as usinas despejando a vinhaça (tratamento comumente dado a esse tipo de resíduo) no leito dos rios, provocando além de um odor insuportável, a mortandade dos peixes. 


\section{Quadro 4 - Variáveis da pesquisa nas dimensões: ambiental, social e econômica}

\begin{tabular}{|c|c|c|c|c|c|c|c|c|}
\hline \multirow{2}{*}{ DIM } & \multirow[t]{2}{*}{ VARIÁVEIS E SUA NATUREZA } & \multirow{2}{*}{\begin{tabular}{|c|}
$\begin{array}{c}\text { Discordo } \\
\text { Fortemente }\end{array}$ \\
1 \\
\end{tabular}} & \multirow{2}{*}{$\begin{array}{c}\text { Discordo } \\
2 \\
\end{array}$} & \multirow{2}{*}{$\begin{array}{c}\begin{array}{c}\text { Sem } \\
\text { Opinialo }\end{array} \\
3\end{array}$} & \multirow{2}{*}{$\begin{array}{c}\text { Concordo } \\
4\end{array}$} & \multirow{2}{*}{\begin{tabular}{|c|}
$\begin{array}{c}\text { Concordo } \\
\text { Fortemente }\end{array}$ \\
5 \\
\end{tabular}} & \multicolumn{2}{|c|}{ Likert } \\
\hline & & & & & & & Média & (DP) \\
\hline \multirow{18}{*}{ 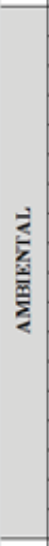 } & 01. Politica Ambiental & & & & & \begin{tabular}{|l|l|l|}
- & & \\
\end{tabular} & 4,63 & 0,99 \\
\hline & 02. Verificação da Politica Ambiental & & & $\leftarrow$ & & & 2,63 & 1,49 \\
\hline & 03. Parcerias para açôes no meio ambiente & & & & & & 3,75 & 1,09 \\
\hline & 04. Grau de compr. com questōes ambientais & & & & & & 4,38 & 0,99 \\
\hline & 05. Avaliação do Impacto ambiental & & & & & & 4,25 & 1,69 \\
\hline & 06. Divulgaçào do desempenho ambiental & & & & & & 2,88 & 1,80 \\
\hline & $07 . \mathrm{N}^{\circ}$ de aspectos ambientais divulgados & & & & & & 3,00 & 1,80 \\
\hline & 08. Manutenção da fauna e da flora & & & & & & 4,38 & 1,11 \\
\hline & 09. Apoio voluntário à conservação ambiental & & & & & & 4,25 & 0,66 \\
\hline & 10. Uso de Defensivos Biodegradsvéis & & & & & & 3,50 & 1,00 \\
\hline & 11. Uso de Herbicidas Biodegradíveis & & & & & & 3,75 & 0,83 \\
\hline & 12. Uso de ténicas eficientes com energia & & & & & & 4,63 & 0,70 \\
\hline & 13. Uso de adubo orgànico no canavial & & & $<$ & & & 3,38 & 1,11 \\
\hline & 14. Adota práticas de conservaçào do solo & & & & & & 4,63 & 0,70 \\
\hline & 15. Cuidados no processo de pulverização & & & & & & 4,50 & 0,87 \\
\hline & 16. Segurança e proteçằ nas pulverizaçð̄es & & & & & & 4,75 & 0,66 \\
\hline & 17. Recollimento e destinaçào de residuos & & & & & & 4,25 & 0,83 \\
\hline & 18. Cuidados tomados em queimadas & & & & & & 4,50 & 1,00 \\
\hline \multirow{2}{*}{ DIM } & \multirow[t]{2}{*}{ VARLÁVEIS E SUA NATUREZA } & $\begin{array}{c}\text { Discordo } \\
\text { Fortemente }\end{array}$ & Discordo & $\begin{array}{c}\text { Sem } \\
\text { Opinialo }\end{array}$ & Concordo & $\begin{array}{l}\text { Concordo } \\
\text { Fortemente }\end{array}$ & \multicolumn{2}{|c|}{ Likert } \\
\hline & & 1 & 2 & 3 & 4 & 5 & Média & (DP) \\
\hline \multirow{15}{*}{ ऐે } & 19. Julgar possuir politica social & & & & & & 4,63 & 0,48 \\
\hline & 20. Qualidade do clima interno da organizaçào & & & & & & 4,50 & 1,00 \\
\hline & 21. Compromisso voluntário com o social & & & & & & 4,88 & 0,33 \\
\hline & 22. Possui regulamen de procedim. internos & & & & & & 4,50 & 1,00 \\
\hline & 23. Avaliação periódica de funcionários & & & & & & 3,50 & 1,32 \\
\hline & 24.Comunicaçào com a comunidade & & & & & & 4,00 & 1,22 \\
\hline & 25. Estim. a particip. do funcionár. com o social & & & & & & 4,00 & 1,00 \\
\hline & 26. Adaptaçăo de deficientes e mulheres & & & & & & 4,00 & 1,22 \\
\hline & 27. Condiçōes de seguran. equipamentos & & & & & & 4,88 & 0,33 \\
\hline & 28. Açōes de cunho social (prática) & & & & & & 4,25 & 1,09 \\
\hline & 29.Treinamento de funcionários (prática) & & & & & ج & 4,88 & 0,33 \\
\hline & 30. Năo utilizaçăo de trabalho forçado & & & & & & 4,88 & 0,33 \\
\hline & 31. Pagtos. dentro da legislaçào, sem atrasos & & & & & & 4,88 & 0,33 \\
\hline & 32. Cumpr. das normas de saúde e segurança & & & & & J & 4,75 & 0,66 \\
\hline & 33. Resp. à legisl. de contratação de deficientes & & & - & & & 3,00 & 1,22 \\
\hline \multirow{2}{*}{ DIM } & \multirow[t]{2}{*}{ VARLÁVEIS E SUA NATUREZA } & $\begin{array}{l}\text { Discordo } \\
\text { Fortement }\end{array}$ & Discordo & $\begin{array}{c}\text { Sem } \\
\text { Opinisło }\end{array}$ & Concordo & $\begin{array}{c}\text { Concordo } \\
\text { Fortemente }\end{array}$ & Like & \\
\hline & & 1 & 2 & 3 & 4 & 5 & Média & (DP) \\
\hline & 34. Divulg. da estratégia de negócios da firma & & & - & & & 3,13 & 1,27 \\
\hline & 35. Procedimentos de qualidade da produçào & & & & & & 4,50 & 0,71 \\
\hline 送 & 36. Relacionamento com clientes pós-vendas & & & & & & 4,38 & 0,86 \\
\hline$\sum_{0}^{n}$ & 37. Alinhamen objetivos e estratégia da empresa & & & & & & 4,50 & 0,87 \\
\hline z⿺ & 38. Preocupaçăo com lucro de nowos negócios & & & & & & 4,40 & 0,99 \\
\hline 通 & 39. Preocupaçăo com geraçăo de novos negócios & & & & & & 4,30 & 0,97 \\
\hline & 40. Percepsầo da importaincia dos residuos & & & & & & 3,88 & 0,93 \\
\hline & 41. Realiz. de estudos e pesq. de cunho econôm. & & & & $\checkmark$ & & 4,25 & 1,30 \\
\hline & & & a de & Zona de & & & & \\
\hline & e: Elaboração própria & Discord & lância & Indiferença & Conco & Idància & & \\
\hline
\end{tabular}


A variável 17 "Recolhimento e destinação dos resíduos" obteve um score 4,25 situando-se medianamente na zona de concordância do modelo (quadro 4).

Com efeito, sob esse capítulo (Dimensão Ambiental) as usinas apresentaram uma atitude totalmente diferente da que apresentavam no passado. Todas sem exceção externaram preocupação para com um tratamento mais condizente de seus resíduos sólidos, inclusive aproveitando-os de maneira econômica para geração de energia (bagaço da cana) e até, produção de adubo para fertirrigação (vinhaça) melhorando a relação adubo químico $x$ adubo orgânico na atividade canavieira.

Seguindo as análises, não foi encontrado nas usinas um Plano de Política Ambiental. Mas, mesmo não cumprindo formalmente esse ideário, as empresas responderam possuir uma "Política ambiental" (Variável 01, média 4,63 no intervalo de Likert). Disseram assumir maior "Grau de compromisso para com as questões ambientais" (Variável 04 com média 4,38) e, proceder a estudos de "Avaliação do impacto ambiental" (Variável 05, nota 4,25) para novos projetos.

Cabe aqui abrir um parêntese para a questão da Variável 18 "Cuidados tomados em queimadas". Indagados sobre a questão das queimadas que tantos problemas trazem para as populações concernidas, todos assentiram que praticavam queimadas, mas de forma controlada e não mais de forma desmedida como antes. Uma das medidas aconselhadas que prevê certo cuidado com a prática das queimadas, é realizar o plantio da cana de forma calculada, para que a colheita coincida com o início das chuvas para facilitar a sedimentação dos poluentes em suspensão. Indagadas sobre esses cuidados, as usinas, não obstante terem afirmado que buscam respeitar as normativas para realização das queimadas, não se referiram em nenhum momento que plantios tenham sido feitos para minimizar esses problemas. Um dos cuidados que é tomado segundo se pode infirmar é o fato de evitarem queimar canavial a certa distância da rede de transmissão de energia elétrica, respeitando o que está estatuído nas normas de proteção.-

Uma percepção que se observou a partir das entrevistas realizadas foi a de que a melhora nas questões ambientais apresentadas pelas usinas está muito mais atrelada ao rigor da fiscalização im- 
posta pelas agências reguladoras do que propriamente uma conscientização por parte do gestor, com vista à obtenção de vantagem competitiva. O que vem corroborar com Haigh e Jones (2006) quando afirmam que pressões regulatórias advindas de governos e organizações não governamentais contribuem para promoção de ações de responsabilidade socioambiental dentro da empresa.

Com efeito, sob esse capítulo é grande o receio das usinas em receberem um processo administrativo-judicial dos fiscais da CPRH ou DRT. O que pode resultar no encerramento de suas atividades. Durante a realização da pesquisa constatou-se que diversas usinas foram fechadas por conta dos passivos resultantes de adequação e conformidade ambiental exigidas por lei.

No universo pesquisado (Quadro 3) havia três empresas (F, $\mathrm{G}, \mathrm{H})$ que já tinham sido autuadas com processo de natureza ambiental nos últimos 03 anos e duas $(B, C)$ com processos de natureza trabalhista, mas que teriam superado as dificuldades.

\subsubsection{Aspectos da dimensão social}

O mesmo risco de multa ambiental ocorre para a usina quando não é cumprida a legislação trabalhista. Assim, invariavelmente todas as usinas pesquisadas demonstraram atenção para com o capítulo do compromisso real com as questões trabalhistas pertencentes à dimensão social do modelo de análise adotado.

E de fato, pela análise detida do quadro 4 vê-se que as maiores médias vão para variáveis ligadas às questões trabalhistas e sociais, a saber: Variável 21 - "Compromisso voluntário com o social" (média 4,88,); V27 - "Condições de segurança dos equipamentos utilizados pelos funcionários" (4,88); V29 - "Treinamento de funcionários", com média 4,88); V30 - "Não utilização de trabalho escravo, nem infantil" (4,88); V31 - "Pagamento de salários dentro da legislação e sem atrasos" $(4,88)$; e V32 - "Cumprimento das normas de saúde e segurança" $(4,88)$. Duas variáveis da dimensão ambiental encerram essas duas preocupações, a trabalhista e o cuidado com o meio ambiente. São elas, a Variável 15 - “Cuidados no processo de pulverização" (média 4,50) e a V16 - "Segurança e proteção nas pulverizações" (médias 4,75). Ambas refletem cuidados com o meio ambiente e com questões do mundo do trabalho. 


\subsubsection{Aspectos da dimensão econômica}

Quanto à dimensão econômica, cuja gestão apresentou-se possuindo foco na geração de novos negócios sustentáveis e na capacidade da usina em se auto sustentar, tem-se as variáveis, V40 "Percepção da importância dos resíduos para rentabilidade da usina" $(3,88)$, a V39 "Preocupação com a geração de novos negócios" $(4,30)$ e a V38 "Preocupação com a rentabilidade na geração de novos negócios" $(4,40)$. Tem-se ainda, como ações importantes na gestão das usinas, a V37 "Alinhamento dos objetivos operacionais (das usinas) com a estratégia da firma" $(4,50)$.

Com efeito, a geração de novos negócios sustentáveis, compõem de forma inequívoca, as estratégias praticadas nas empresas da região. Trata-se da geração de energia térmica e/ou elétrica com o aproveitamento de resíduos e a fabricação de fertilizantes com o aproveitamento da vinhaça. Foram também encontradas pesquisas sendo desenvolvidas para a implementação de novas fontes de renda no período da entressafra (ver quadro 4).

Vê-se ainda sob o prisma do tripé da sustentabilidade, a combinação da variável V35 "Procedimentos para qualidade da produção" $(4,50)$ (ligada à dimensão econômica) com a variável V10 (da dimensão ambiental) "Uso de Defensivos Biodegradáveis" $(3,50)$. Ambas tendo obtido score significativo no olhar das empresas.

\section{Síntese do comportamento observado quanto às práticas gerenciais adotadas}

Procedendo aqui uma primeira tentativa de síntese quanto ao comportamento das usinas em relação aos preceitos da RSAE vemos claramente que sua gestão segue dois eixos balizadores: a) a uma, a preocupação com o aproveitamento de forma econômica e que favorece ao meio ambiente, dos resíduos provenientes da atividade canavieira. Conta-se ai a transformação por todas as empresas do resíduo "bagaço da cana" em energia. Também o aproveitamento do uso da vinhaça para fabricação de fertilizantes que são aproveitados e/ou vendidos para fertirrigação dos próprios canaviais; b) a duas, a preocupação quanto ao cumprimento das exigências legais de inspiração trabalhista e ambiental. Toda essa observação pode ser verificada na preocupação que as empresas demonstraram ter 
com questões como: manutenção da fauna e da flora (V08, 4,38), segurança e proteção nas pulverizações (V16, 4,75), pagamento dentro da legislação sem atrasos (V31, 4,88), condições de segurança dos equipamentos $(V 27,4,88)$ e, cumprimentos das normas de saúde e segurança (V32, 4,75).

Assim, a preocupação com o desenvolvimento de "novos negócios sustentáveis" e o "atendimento às normas legais" (esforço para cumprimento das normas legais) caracterizam o eixo central das ações empreendidas pelas empresas no que tange a sua busca de adequação (mesmo que de forma indireta) aos preceitos da RSAE. Podemos até supor que esse comportamento, detentor de certo grau de responsabilidade ambiental e social, não advenha propriamente de uma maior conscientização da empresa sobre a importância de incluir práticas ecologicamente corretas com vistas a fortalecer sua imagem e com isso alcançar novos mercados. Mas, como uma proteção em face à necessidade de cumprimento da legislação trabalhista e, sobretudo, a fiscalização dos órgãos responsáveis pela observação das leis ambientais e o risco de multa que lhe é inerente. Isso de certa forma pode ser deduzido a partir de entrevistas que se realizou com representantes e técnicos dos órgãos reguladores, cujo propósito não era outro senão, possibilitar uma triangulação de respostas obtidas (Fig. 2).

\section{Figura 2 - Entidades participantes do levantamento de dados}

Gestores das Usinas

de Cana de Açúcar
Sindicato (Sindaçucar)

EECAC - Estação de Cana de

Carpina, Associações Rurais
Órgãos Regulamentadores

(CPRH, DRT)

Fonte: Elaboração própria

\subsection{A existência de grupos diferenciados de empresas na gestão da RSAE}

Durante as entrevistas observou-se que havia um comportamento diferenciado por parte de algumas empresas em relação à algumas variáveis pesquisadas. Buscando confirmar esse entendi- 
mento foi procedida uma análise de cluster cujo propósito era o de validar essa hipótese. A diferenciação nesse caso foi sentida a "olho nu", observada durante as entrevistas.

\subsubsection{Análise de cluster}

Pelo resultado da análise de cluster vê-se existir uma diferenciação de comportamento por parte das usinas do setor em relação a algumas variáveis (Figura 3).

No caso em epígrafe, dando um corte do segundo nível no Dendrograma da Figura 3, tem-se que, as usinas mais afeitas à observação das questões socioambientais sendo respectivamente, as usinas (1), (2) e (5) (usinas do Grupo 1). O outro grupo, (Grupo 2) sendo constituído pelas usinas (4), (8), (7), (3) e (6), podendo ser considerado como grupo de usinas menos ligadas à ação socioambiental com relação aos aspectos pesquisados.

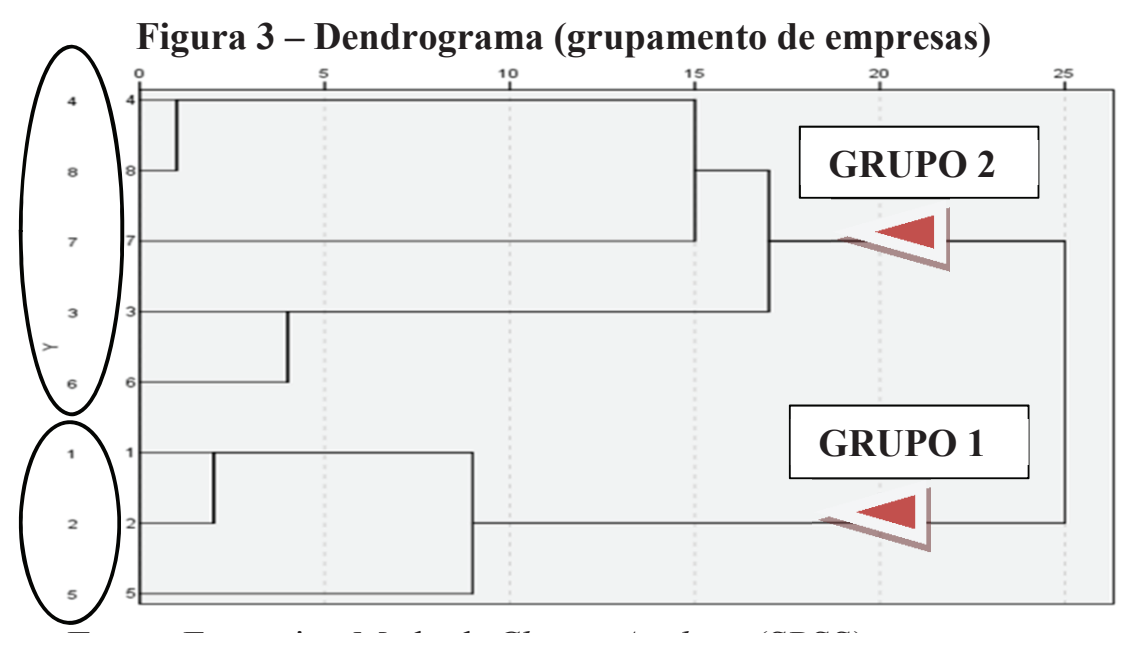

Fonte: Extraction Method: Cluster Analysis (SPSS)

No caso em epígrafe, dando um corte do segundo nível no Dendrograma da Figura 3, tem-se que, as usinas mais afeitas à observação das questões socioambientais sendo respectivamente, as usinas (1), (2) e (5) (usinas do Grupo 1). O outro grupo, (Grupo 2) sendo constituído pelas usinas (4), (8), (7), (3) e (6), podendo ser considerado como grupo de usinas menos ligadas à ação socioambiental com relação aos aspectos pesquisados. 
3.3.2 Teste de hipóteses sobre práticas diferenciadas de gestão entre os grupos G1 e G2 (método da diferença entre duas médias)

Nessa seção buscar-se-á validar estatisticamente a percepção de que os grupos possuem comportamentos diferenciados em relação a algumas variáveis à luz da aplicação de um método estatístico que permite mensurar o grau de diferenciação.

Esse método já destacado na metodologia é o teste da diferença entre duas médias observadas entre os elementos de uma dada população com base em duas amostras tiradas aleatoriamente. Considera-se que se as duas amostras tiverem sido retiradas de uma mesma população, nesse caso a diferença existente entre as duas médias não seria estatisticamente significativa (Ho) e os comportamentos tidos como iguais. Se Ho for rejeitada, considera-se que as médias são de fato diferentes. No estudo em tela considerou-se como zona de aceitação para Ho a área equivalente a 90\% debaixo da curva de distribuição teórica $t$ de student. Sendo a área de rejeição fixada em $\pm 5 \%$ para cada lado da curva. O valor de $t$ na tabela de efetivos teóricos ficou em $\pm 1,943$. Também se definiu o valor de $t$ para uma área de rejeição (Ho) maior $( \pm 10 \%)$. Para esse caso o valor de $t$ ficou em $\pm 1,440$ na tabela (modelo na Figura 4).

\section{Figura 4 - Distribuição de $\mathbf{t}$ (Lei de Student)}

Fonte: Elaboração própria

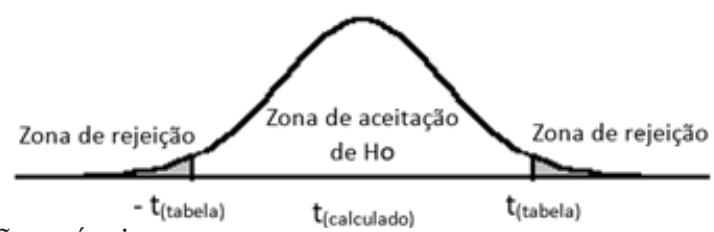

O passo seguinte é a aplicação do modelo aos dados da pesquisa, buscando a partir da média dos grupos (G1) e (G2) para cada variável, obter os $t_{\text {(calculados) }}$ a fim de compara-los com os $t_{\text {(teóricos) }}$ da tabela $t$ de Student (para os níveis $\pm 5 \%$ e $\pm 10 \%$ ). O objetivo é o de verificar a rejeição ou a não-rejeição (aceitação) da hipótese nula (Ho) para cada variável.

Nesse contexto as variáveis cujas hipóteses nulas forem rejeitadas, se constituirão no espaço discriminante procurado (Quadro 5). O $t$ de Student seguindo a teoria, é calculado a partir das seguintes fórmulas: $/(1)$; onde $=\left[\sum\left(x_{i}-x_{1}\right)^{2}+\sum\left(x_{j}-x_{2}\right)^{2}\right] /\left(n_{1}+n_{2}-2\right)(2)$; onde e são respectivamente médias dos grupos G1 e G2 da amostra considerada. 


\section{Quadro 5 - Teste da diferença entre duas médias segundo as dimensões do Triple Bottom Line}

\begin{tabular}{|c|c|c|c|c|c|c|}
\hline \multirow{2}{*}{ DIM. } & \multirow{2}{*}{ Variảveis } & \multicolumn{2}{|c|}{ Médias } & \multicolumn{3}{|c|}{ Teste da diferença entre duas médias } \\
\hline & & $\overline{\mathbf{X}} \mathbf{G 1}$ & $\overline{\mathbf{X}} \mathbf{G} 2$ & t(calc.) & $\mathrm{ZC}=0,05 ; \mathrm{t}>1,94$ & $\mathrm{ZC}=0,10 ; \mathrm{t}>1,44$ \\
\hline \multirow{18}{*}{$\frac{\sum}{\sum_{2}^{2}}$} & \multirow{18}{*}{$\begin{array}{l}\text { 01. Política Ambiental (entender que possui) } \\
\text { 02.Verificação Politica Ambiental Interna } \\
\text { 03 Parcerias para açð̃es no meio ambiente } \\
\text { 04. Grau de compromet. c/ questðes ambientais } \\
\text { 05. Avaliação do impacto ambiental (efetuar) } \\
\text { 06. Divulgação do desempenho ambiental } \\
\text { 07 Número de aspectos ambientais divulgados } \\
\text { 08. Manutenção da fauna e da flora (atenção) } \\
\text { 09. Apoio voluntário à conservação ambiental } \\
\text { 10.Uso de defensivos agrícolas biodegradáveis } \\
\text { 11.Uso de herbicidas biodegradáveis } \\
\text { 12.Uso de técnicas eficientes de energia } \\
\text { 13.Uso de adubo orgânico no canavial } \\
\text { 14. Adota práticas de conservação de solo } \\
\text { 15. Cuidados no processo de pulverização } \\
\text { 16.Segurança no processo de pulverização } \\
\text { 17.Recolhimento e Destinação de Residuos } \\
\text { 18 Cuidados adotados em queimadas }\end{array}$} & 5,00 & 4,40 & 0,75 & H0 aceita & HO aceita \\
\hline & & 2,70 & 2,60 & 0,5 & H0 aceita & HO aceita \\
\hline & & 4,00 & 3,80 & 0,44 & HO aceita & HO aceita \\
\hline & & 4,70 & 4,20 & 0,57 & H0 aceita & HO aceita \\
\hline & & 5,00 & 3,80 & 1,54 & H0 aceita & Ho rejeitada \\
\hline & & 3,70 & 2,40 & 0,95 & H0 aceita & HO aceita \\
\hline & & 3,70 & 2,60 & 0,73 & H0 aceita & HO aceita \\
\hline & & 5,00 & 4,00 & 1,19 & H0 aceita & HO aceita \\
\hline & & 4,70 & 4,00 & 1,37 & H0 aceita & H0 aceita \\
\hline & & 2,70 & 4,00 & 2,07 & Ho rejeitada & Ho rejeitada \\
\hline & & 3,30 & 4,00 & 1,04 & H0 aceita & H0 aceita \\
\hline & & 4,30 & 4,80 & 0,84 & H0 aceita & H0 aceita \\
\hline & & 3,30 & 3,40 & 0,07 & H0 aceita & \\
\hline & & 4,30 & 4,80 & 0,84 & H0 aceita & H0 aceita \\
\hline & & 4,30 & 4,60 & 0,37 & H0 aceita & HO aceita \\
\hline & & 4,30 & 5,00 & 1,37 & H0 aceita & HO aceita \\
\hline & & 3,30 & 4,80 & 4,06 & Ho rejeitada & Ho rejeitada \\
\hline & & 4,00 & 4,80 & 1,06 & H0 aceita & H0 aceita \\
\hline \multirow{2}{*}{ DIM. } & \multirow{2}{*}{ Variáveis } & \multicolumn{2}{|c|}{ Médias } & \multicolumn{3}{|c|}{ Teste da diferença entre duas médias } \\
\hline & & $\overline{\mathbf{X} G 1}$ & $\overline{\mathbf{X}} \mathbf{G} 2$ & t(calc.) & $\mathrm{ZC}=0,05 ; \mathrm{t}>1,94$ & $\mathrm{ZC}=0,10 ; \mathrm{t}>1,44$ \\
\hline \multirow{15}{*}{ 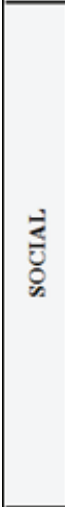 } & \multirow{15}{*}{$\begin{array}{l}\text { 19. Julgar possuir politica social } \\
\text { 20. Qualid. do clima interno da Organiz. } \\
\text { 21 Compromisso voluntário com o social } \\
\text { 22. Possuir regulamento interno padrào } \\
\text { 23. Avaliação periódica de funcionários } \\
\text { 24 Comunicação com a comunidade } \\
\text { 25.Estimulo particip. do funcion. com o Social } \\
\text { 26.Adaptaç. de defic. e mulheres ao trabalho } \\
\text { 27.Condiçoses seguranç. e equip. adequados } \\
\text { 28. Açð̃es de cunho social (prática) } \\
\text { 29.Treinamento de funcionários (prática) } \\
\text { 30.Não utilização de trabalho forçado } \\
\text { 31.Cumprim. do pagto. sem atrasos } \\
\text { 32.Cumpr. das normas de saúde e segurança } \\
\text { 33. Respeito à leg. de contrat. de deficientes } \\
\end{array}$} & 5,0 & 4,4 & 1,84 & H0 aceita & Ho rejeitada \\
\hline & & 4,7 & 4,4 & 0,32 & H0 aceita & H0 aceita \\
\hline & & 5,0 & 4,8 & 0,75 & H0 aceita & H0 aceita \\
\hline & & 5,0 & 4,2 & 0,80 & H0 aceita & H0 aceita \\
\hline & & 4,7 & 2,8 & 2,29 & Ho rejeitada & Ho rejeitada \\
\hline & & 4,7 & 3,6 & 1,14 & H0 aceita & H0 aceita \\
\hline & & 5,0 & 3,4 & 3,00 & Ho rejeitada & Ho rejeitada \\
\hline & & 4,7 & 3,6 & 1,14 & H0 aceita & HO aceita \\
\hline & & 5,0 & 4,8 & 0,75 & HO aceita & HO aceita \\
\hline & & 4,7 & 4,0 & 0,76 & H0 aceita & H0 aceita \\
\hline & & 5,0 & 4,8 & 0,75 & H0 aceita & H0 aceita \\
\hline & & 5,0 & 4,8 & 0,75 & H0 aceita & HO aceita \\
\hline & & 4,7 & 5,0 & 1,37 & H0 aceita & H0 aceita \\
\hline & & 4,3 & 5,0 & 1,37 & H0 aceita & HO aceita \\
\hline & & 2,3 & 3,4 & 1,14 & H0 aceita & HO aceita \\
\hline \multirow{2}{*}{ DIM. } & \multirow{2}{*}{ Variáveis } & \multicolumn{2}{|c|}{ Médias } & \multicolumn{3}{|c|}{ Teste da diferença entre médias } \\
\hline & & $\overline{\mathbf{X}} \mathbf{G 1}$ & $\overline{\mathbf{X}} \mathbf{G} 2$ & t(calc.) & $\mathrm{ZC}=0,05 ; \mathrm{t}>1,94$ & $\mathrm{ZC}=0,10 ; \mathrm{t}>1,44$ \\
\hline \multirow{8}{*}{ 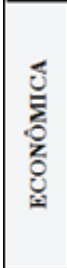 } & \multirow{8}{*}{$\begin{array}{l}\text { 34. Divulgação da estratégia de negócios } \\
\text { 35.Procedimentos de qualidade da produção } \\
\text { 36.Relacionamento com clientes pós-vendas } \\
\text { 37.Alinh. entre objetivos e estratég. da empresa } \\
\text { 38.Preocup. c/ novos negócios (residuos) } \\
\text { 39. Preocup. com a geração de novos negócios } \\
\text { 40.Percepção da importância econ. dos residuos } \\
\text { 41.Realização de estudos de cunho econômico }\end{array}$} & 3,3 & 3,0 & 0,31 & \begin{tabular}{|c|} 
H0 aceita \\
\end{tabular} & H0 aceita \\
\hline & & 4,0 & 4,8 & 1,60 & HO aceita & Ho rejeitada \\
\hline & & 4,3 & 4,4 & 0,09 & H0 aceita & H0 aceita \\
\hline & & 4,3 & 4,6 & 0,37 & H0 aceita & H0 aceita \\
\hline & & 4,7 & 4,2 & 0,57 & H0 aceita & HO aceita \\
\hline & & 4,7 & 4,0 & 0,87 & H0 aceita & H0 aceita \\
\hline & & 4,7 & 3,4 & 2,16 & Ho rejeitada & Ho rejeitada \\
\hline & & 4,0 & 4,4 & 0,37 & $\mathrm{H} 0$ aceita & H0 aceita \\
\hline
\end{tabular}

Fonte: Elaboração própria 


\subsection{Emergência do Espaço discriminante das práticas de gestão das empresas G1 e G2 e suas estratégias de dife- renciação}

Aplicando-se o modelo estatístico adotado da diferença entre duas médias para os Grupos G1 e G2 (Quadro 5) após cotejamento entre os $t_{\text {(calculados) }}$ com os $t_{\text {(téricos) }}$ considerando então as variáveis cujas hipóteses nulas (Ho) foram rejeitadas, endereça-se o espaço discriminante apresentado no Quadro 6 cujas variáveis são tidas como significativamente diferentes com respeito às práticas gerenciais dos dois grupos considerados. As variáveis cujas médias foram consideradas iguais (Ho não-rejeitada) são tidas como práticas gerenciais inter-grupos cujas diferenças são, "não-significativas".

As análises que se seguem avançam no sentido de sintetizar sobre que aspectos os comportamentos dos grupos G1 e G2 são diferentes.

Quadro 06 - Espaço discriminante das práticas de gestão dos Grupos 1 e 2

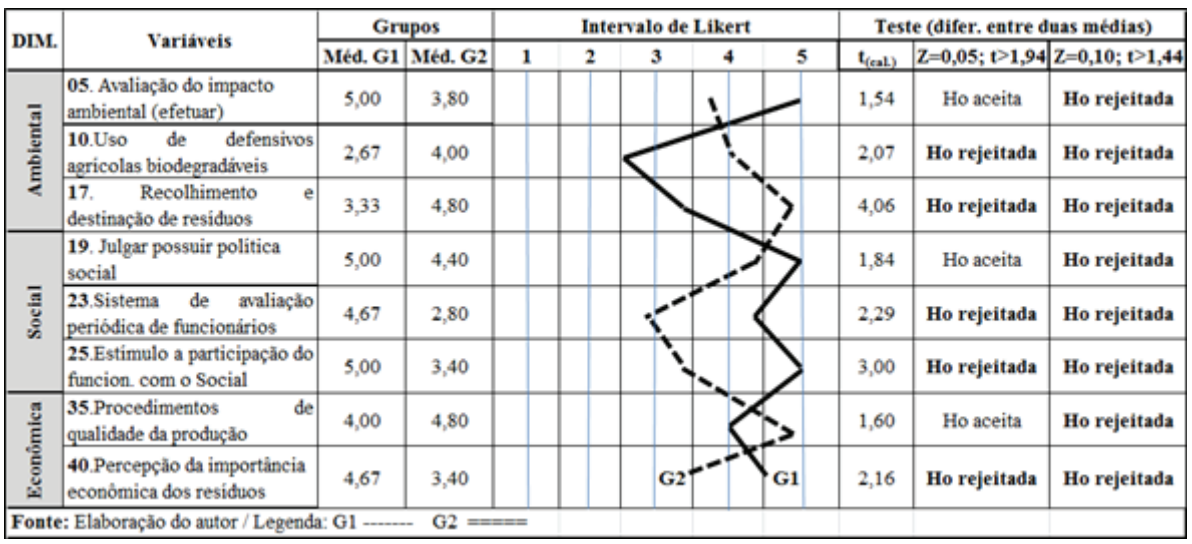

\subsubsection{Estratégia de diferenciação - Grupo 1}

Para as empresas do Grupo 1 vê-se como práticas diferenciadas onde apresentam melhor desempenho que as empresas do Grupo 2, a variável ambiental V05 (Efetuar avaliação do impacto ambiental), todas as variáveis da dimensão social do Quadro 6, a saber, V19 (Julgar possuir política social), V23 (Sistema de avaliação periódica de funcionários) e V25 (Estímulo à participação do funcio- 
nário com o social) e ainda, uma variável da dimensão econômica, V40 (Percepção da importância econômica dos resíduos) todas figurando como práticas diferenciadas, melhor desempenhadas pelas empresas do Grupo 1 comparativamente às do Grupo 2.

Denota assim preocupação com a RSAE no que diz respeito à melhoria da qualidade de suas ações ambientais dado que procede avaliações do impacto ambiental, uma maior preocupação com políticas sociais (desenvolve política social), procura avaliar periodicamente funcionários e os apoia em atividades ligadas ao social. E por fim, procura incorporar novos negócios sustentáveis demonstrando uma maior percepção para a importância econômica quanto ao aproveitamento dos resíduos da atividade canavieira.

\subsubsection{Estratégia de diferenciação - Grupo 2}

Analisando a estratégia de diferenciação do Grupo 2 em relação às empresas do Grupo 1, observando o espaço discriminante do Quadro 6, na dimensão ambiental, chama-se a atenção a pertinência da variável 10 (Uso de defensivos agrícolas biodegradáveis) apresentar uma média muito superior a das empresas do Grupo 1. Respectivamente, média 4,00 (G2) contra 2,67 (G1).

Também a variável 17 (Recolhimento e destinação de resíduos) denotando assim uma preocupação de cunho ambiental com o correto descarte dos resíduos. Respectivamente, médias de 4,00 (G2) contra 2,67 (G1) e 4,80 (G2) contra 3,33 (G1).

Isso pode significar que as empresas do Grupo 2, como uma forma de compensar práticas gerenciais menos voltadas para a RSAE comparativamente às empresas do Grupo 1, estejam procurando se voltar para o atendimento de um mercado mais seletivo em termos qualitativos (nichos de mercado), buscando tornar-se fornecedoras de empresas multinacionais, tais como Coca-Cola e outras. Que passam a exigir em seu caderno de encargos, posturas ambientais e até sociais, específicas. Tudo isso foi observado nas entrevistas semidiretivas no levantamento de dados. A busca por um melhor comportamento ambiental dessas usinas $(3,4,6,7,8)$ pode ser constatado na Tabela 03 onde todas desse grupo, procuraram obter um certificado ou um prêmio ambiental que seja, mesmo que outorgado por instituições locais. 
A hipótese pela busca de um nicho de mercado é reforçada quando se analisa no Quadro 6, a variável 35 (Procedimentos de qualidade da produção) onde a média apresentada pelo conjunto de empresas do Grupo $2(4,80)$ foi superior à média do conjunto de empresas do Grupo $1(4,00)$ e considerada "significativamente diferente". O que corrobora com a tese de um eventual maior esforço empreendido pelo Grupo 2 em se destacar no quesito "qualidade da produção" com suposta maior eco-eficiência. Para responder aos imperativos de seus clientes internacionais?

Em entrevista fortuita em um seminário da área (SOBER - 2016) realizado em Maceió - AL em agosto de 2016, teve-se a oportunidade de conversar a respeito desse tema (fornecimento de açúcar à empresas multinacionais pelas usinas da região) com uma técnica ligada à questões de qualidade da produção na fabricação de açúcar. Ela teria dito que:

“... os talhões ligados ao plantio da cana para fabricação de açúcar em atendimento a contratos com empresas multinacionais, 'parecem não ser desse planeta'. Tudo é rigorosamente respeitado e cumprido; desde a questão ambiental, até a social. Atuam como se estivessem de prontidão para uma eventual inspeção a qualquer tempo" (Técnica responsável pelo controle de qualidade em usinas da região, Maceió - AL, SOBER 2016).

Deixa-se em aberto, as reflexões que podem se desprender dessa última assertiva no que tange a influência das características socioculturais de cada região e sua interferência nas escolhas estratégicas da firma. Perspectiva esta, colocada no início do estudo de maneira ancilar ao enunciado da questão-problema para ser respondida empiricamente pela pesquisa.

Essa discussão será retomada em seguida nas considerações finais.

\section{CONSIDERAÇões FINAIS}

O presente trabalho se esmerou em estudar, que práticas de gestão são desenvolvidas pelas empresas do setor sucroalcooleiro de uma região tradicionalmente produtora, recaindo o estudo sobre 
13 usinas de cana-de-açúcar do estado de Pernambuco. O intuito, o de verificar no setor, a modernização da administração conforme os preceitos que regem o conceito de Responsabilidade Socioambiental Empresarial (RSAE).

Verificou-se a partir da análise de dados junto aos gestores das unidades pesquisadas e seus stakholders, que a forma de administração praticada, de fato busca ser desenvolvida de maneira rentável (dimensão econômica) desempenhando atividades ligadas à geração de energia a partir do aproveitamento de resíduos sólidos derivados da atividade canavieira (dimensão ambiental) ao mesmo tempo em que procura atender aos requisitos da legislação trabalhista (dimensão social).

A deduzir pelo comportamento médio apresentado pelas empresas estudadas, pode-se dizer que a responsabilidade socioambiental empresarial (RSAE) existe (ainda que de forma tênue) na prática gerencial das usinas do setor em análise. Com certeza, não como uma prática gerencial consolidada, implantada intencionalmente com o fito de obter vantagem competitiva face à concorrência como intenta até com certa lógica estatuir a teoria (CARROLL, 1991; AAKER, D. et al., 2012; CORAL, 2002; BARBIERI, 2011; MELO NETO e FROES, 2011; NEVES, 2010; OLIVEIRA, D. R. P. 2014; MINTZBERG, H. et al., 2010; ZYLBERSZTAIN e LINS, 2010).

Mas ao inverso, no caso em estudo, as empresas apresentaram como característica mais forte, o fato de as variáveis relacionadas à RSAE estarem sendo cumpridas muito mais como uma estratégia de defesa frente à necessidade em atender aos requisitos da legislação trabalhista e ambiental.

Nesse sentido, esse comportamento se aproxima mais com o preconizado por Haigh e Jones (2006) quando enfatizam que as ações de responsabilidade socioambiental dentro das empresas sofrem a influência de fatores tais como a pressão interna sobre os gerentes de negócios, pressão dos compradores, mas, sobretudo, de pressões regulatórias que vêm de governos e organizações não governamentais. No caso em estudo, pressão das agências de regulação ambiental (CPRH) e das associações de trabalhadores rurais e seus sindicatos como stakeholders. Tudo isso para não correr riscos de passivo trabalhista e/ou ambiental que pode ser fatal aos negócios. Como ficou muito bem claro nas entrevistas. 
Outro fator de influência que pode levar a empresa a promover ações de RSAE são as exigências de selos de conformidade social e ambiental impostas por firmas multinacionais como condição para adquirir seus produtos, como sugere ser o caso preciso das empresas do Grupo 2 como fornecedoras de açúcar para empresas estrangeiras, citando-se a Coca Cola e suas coligadas como exemplo.

O compromisso com a sustentabilidade, de acordo com o entendimento de Zylbersztain e Lins (2010), "faz com que a estrutura organizacional se preocupe em desfazer-se de práticas consideradas ultrapassadas, caracterizadas por uma antiga gestão e busque estabelecer uma nova postura, mais comprometida com as atividades desenvolvidas na empresa no aspecto social, econômico e ambiental". Vale dizer, com práticas mais sustentáveis no geral.

Vê-se aqui no exemplo, como a "adaptação" à exigência de um selo de conformidade ambiental por parte de empresas multinacionais, segue um trajeto peculiar, não ortodoxo, influenciado pelas práticas gerenciais características da região. Perspectiva aventada no início do estudo como negligenciada pela teoria.

Com efeito, edifica-se uma espécie de gestão paralela diferenciada, para tratar das condições ligadas à qualidade dos talhões que pouco tem a haver com a prática corriqueira empregada na administração da usina como um todo. Assim, não está totalmente correto que essa condição (exigência de conformidade através de selos de qualidade) fará com que a estrutura organizacional se preocupe em buscar estabelecer uma nova postura mais comprometida com as atividades sustentáveis na empresa, conforme aludido pela teoria.

Esse alinhamento, considerando as características de cada região e condições específicas de sua gestão, pode não se dar automaticamente como prática disseminável para toda a empresa. Caso vivo de algumas usinas de cana-de-açúcar de uma região tradicionalmente produtora como o Nordeste do país. Constatação com base no comportamento de usinas estudadas nos estados de Alagoas e Pernambuco (53\% da produção de cana-de-açúcar da região do NE brasileiro). E que dentro de seus limites, pode ser estendida a muitas empresas da região.

Assim, o fato de a teoria não considerar a influência das características regionais no comportamento da firma em termos de RSAE, carece de precisão. 
Mas está visto que quando a empresa o deseja, ou é pressionada, ela cumpre com os requisitos socioambientais. Percebe-se no geral, que não há mais espaço para a atuação de forma improvisada das usinas, sem profissionalismo, ou seja, não existem mais grupos de usinas (de sucesso) que não procurem atender às condições mínimas necessárias de conformidade com as obrigações legais.

O entendimento do estudo quanto ao conceito de sustentabilidade é a de a sobrevivência das usinas face a um contexto cada vez mais dáinâmico do setor, imporá o aperfeiçoamento de sua gestão com inclusão cada vez mais premente de práticas de responsabilidade social, econômica e ambiental (RSAE) às suas empresas.

Como última conclusão, a de que foram identificados na região, dois grupos de empresas (G1 e G2), um apresentando maior familiaridade com as práticas de gestão voltadas para o ambiental e o social, e outro, menos. Observação que pode ser verdadeira para outras usinas em funcionamento no nordeste do país, região de concentração do estudo.

Cita-se como limitação da pesquisa o fato de não se ter podido ampliar por questões de ordem financeira o número de usinas pesquisadas inserindo no estudo, as unidades do estado vizinho de Alagoas que juntas com as de Pernambuco, respondem por mais de $50 \%$ da produção de açúcar do Nordeste.

E por fim como sugestão à extensão do trabalho, pesquisas futuras poderiam ser empreendidas no sentido de compreender quais características na equipe gestora dessas unidades produtivas (usinas) são mais determinantes para explicar as diferenças de conduta encontradas nas práticas gerenciais.

\section{REFERÊNCIAS}

AAKER, D. A.; HAAG, M. A.; MEIRA, P. R. Administração estratégica de mercado. 9. ed. Porto Alegre: Bookman, 2012.

ALCARDE, A. R. Árvore do conhecimento cana-de-açúcar. Brasília: Embrapa Ageitec. 2012. disponível em: http://www.agencia.cnptia.embrapa.br/gestor/cana-de-acucar/arvore/CONTAG01_108_22122006154841.html. Acesso em: 21 mai. 2015.

BALBINO, V. A.; BINOTTO, E.; SIQUEIRA, E. S. Apicultura e Responsabilidade Social: desafios da produção e dificuldades em adotar práticas social e ambientalmente responsáveis.

Revista Eletrônica de Administração, Porto Alegre, v.21, n.2, p.348-377, maio/ago. 2015 
BANERJEE, S. B. Corporate social responsibility: the good, the bad, and the ugly.

Cheltenham: Edward Elgar Publishing Limited, 2007.

BARBIERI, J. C. Gestão ambiental empresarial: conceitos, modelos e instrumentos. 2. ed. São Paulo: Saraiva, 2011.

BARDIN, L. Análise de conteúdo. 6. ed. São Paulo: Edições, 2011.

BUENO, M. P.; SOUZA, A.; MEIRELES, E. Sustentabilidade Empresarial na Usina de Açúcar a Alcool: Conceitos e Indicadores. In: ENCONTRO NACIONAL DE ENGENHARIA DA PRODUÇÃO (ENEGEP), 31, 2011, Belo Horizonte. Anais... Belo Horizonte, 2011. Disponível em : http://www.abepro.org.br/indexsub.asp?ss=38. Acesso em: 08 set. 2015.

CARROLL, A. The pyramind of corporate Social Responsability:toward the moral management of organizational stakeholders. Business Horizons, Amsterdam, v. 34, n.4, p.39-48, jul./ago.1991.

COMISSÃO MUNDIAL SOBRE MEIO AMBIENTE E DESENVOLVIMENTO. Nosso futuro comum. Rio de Janeiro: Editora da Fundação Getúlio Vargas, 1988.

CORAL, E. Modelo de Planejamento estratégico para sustentabilidade empresarial. Florianópolis, 2002. 282f. Tese (Doutorado em Engenharia da Produção) - Programa de Pós Graduação em Engenharia da Produção, Universidade Federal de Santa Catarina.

CORRAR, L. J.; EDILSON, P.; DIAS FILHO, J. M. Análise Multivariada. São Paulo: Atlas, 2009.

DONI, M. V. Análise de Cluster: métodos hiérarquicos e de particionamento. São Paulo, 2004. 93f. Trabalho de Conclusão de Curso (Graduação) - Universidade Presbiteriana Mackenzie. Disponível em: http://meusite.mackenzie.com.br/rogerio/tgi/2004Cluster.PDF. Acesso em: 23 nov. de 2016.

ELKINGTON, J. Enter the Triple Bottom Line. In: HENRIQUES, A.; RICHARDSON, J. The Triple Bottom Line, Does It All Add Up?: Assessing the Sustainability of Business and CSR. 1. ed., Earthscan: Publications Ltd., 2004, cap. 1, p. 1-16. Disponível em: http://www.johnelkington. com/archive/TBL-elkington-chapter.pdf. Acesso em: 28 abr. de 2015.

GOMES, P. R. Indicadores Ambientais na discussão da sustentabilidade: uma proposta de análise estratégica no contexto do etanol da cana-de-açúcar do estado de São Paulo. São Paulo, 2011. 166f. Dissertação de Mestrado do Programa de Engenharia Ambiental da Escola de Engenharia de São Carlos, Universidade de São Paulo.

HAIGH, M.; JONES, M. T. The drivers of corporate social responsibility: a critical review. The Business Review. Cambridge, v. 5, n. 2, p. 245-251, 2006.

INSTITUTO BRASILEIRO DE DEFESA DA NATUREZA - IBDN. Selos de Sustentabilidade Por que levar para minha empresa. São Paulo: OSCIP-Ibdn, 2017. Disponível em: http://www. ibdn.org.br/2017/07/12/selos-de-sustentabilidade-porque-levar-para-minha-empresa/. Acesso em: 18 abr. 2017.

INSTITUTO ETHOS DE EMPRESAS E RESPONSABILIDADE SOCIAL. Incentivando a Gestão Empresarial Socialmente Responsável. São Paulo: Ethos, 2016. Disponível em: https://www3. ethos.org.br/conteudo/gestao-socialmente-responsavel/publico-interno/\#.WT7AqmjytRY. Acesso em: 23 ago. 2016. 
MATTIOLI, J. W.; CASTRO, D. S. P.; CLARO, J. A. C. S.; VIEIRA, A. M.; SPERS, V. R. E. Corporate social responsibility and its role in the small business scenario. Nucleus (Ituverava. Impresso), v. 12, p. 285-302, 2015.

MINISTÉRIO DA AGRICULTURA E PRODUÇÃO AGROPECUÁRIA (Dados de Cana-de-Açúcar, Safra de 2016/2017) Dísponivel em:< http://www.agricultura.gov.br/assuntos/ sustentabilidade/agroenergia/arquivos-producao/copy5_of_ac_prodtipo_1617.pdf. Acesso em: 31 dez. 2016.

MELO NETO, F. P.; FROES, C. Gestão da responsabilidade social corporativa: o caso brasileiro. Rio de Janeiro: Qualitymark, 2010.

MELO NETO, F. P.; FROES, C. O bem- feito: os novos desafios da gestão de responsabilidade socioambiental sustentável corporativa. Rio de Janeiro: Qualitymark, 2011.

MINTZBERG, H.; AHLSTRAND, B.; LAMPEL, J. Safári de estratégia: um roteiro pela selva do planejamento estratégico. 2. ed. Porto Alegre: Bookman, 2010.

MONJALLON, A. Introduction à la Méthode Statistique. 7. ed. Paris: Vuibert, 1980.

MUNASINGHE, M. Addressing sustainable development and climate change together using sustainomics. Wiley, J. e Sons, Ltd. 2010. Disponível em: http://www.mohanmunasinghe.com/ pdf/WILEY-Wires-CC-SD-Oct2010.pdf . Acesso em: 13 fev.14.

NASCIMENTO, L. F.; LEMOS, D.; MELLO, M. C. A. Gestão Socioambiental Estratégica. Porto Alegre: Bookman, 2008.

NEVES, M. F. (Coordenador). Agronegócios e desenvolvimento sustentável: uma agenda para a liderança mundial na produção de alimentos e bioenergia, 1a․ed., São Paulo: Atlas, 2007.

NEVES, M. F.; CONEJERO, A. M. Estratégias para a cana no Brasil: um negócio classe mundial. 1. ed. São Paulo: Atlas, 2010

OLIVEIRA, D. P. R. Estratégia empresarial \& vantagem competitiva: como estabelecer, implementar e avaliar. 9ª ed. São Paulo: Atlas, 2014.

PESTANA, M. H.; GAGEIRO, J. N. Análise de dados para ciências sociais: a complementariedade do SPSS. 6 6. ed. Lisboa: Edições Sílabo, 2014.

POPE, J.; ANNANDALE, D.; MORRISONSAUNDERS, A. Conceptualising sustainability assessment. Environmental Impact Assessment Review, Grã-Bretanha, v. 24, n. 6, p. 595-616, 2004.

RABELO, N. S.; SILVA, C. E. Modelos de indicadores de responsabilidade socioambiental corporativa. Revista Brasileira de Administração Científica, Aquidabã, v.2, n.1, jun.2011.

ROESCH, S. M. A. Projetos de Estágio e de pesquisa em Administração: guia para estágios, trabalhos de conclusão, dissertação e estudos de caso. São Paulo: Atlas, 2005.

SACHS, I. Caminhos para o desenvolvimento sustentável. In: STROH, P. Y. (Org.) Coleção idéias Sustentáveis. Rio de Janeiro: Garamond, 2000. p. 96.

SANCHES, C. S. Gestão ambiental proativa. Revista de Administração de Empresas, RGRS, v. 40, n. 1, p. 76-87, 2000. 
SERVIÇO BRASILEIRO DE APOIO ÀS MICRO E PEQUENAS EMPRESAS (SEBRAE). O que pensam as micro e pequenas empresas sobre sustentabilidade. Série estudos e pesquisas, Brasília. maio/2012. Disponível em: http://sustentabilidade.sebrae.com.br/Sustentabilidade/ Para $\% 20$ sua $\% 20$ empresa/Estudos $\% 20 \mathrm{e} \% 20$ Pesquisas/O+que+Pensam+as+Micro+e+Pequenas+ Empresas+sobre+Sustentabilidade.pdf >, Acesso em: 08 set. 2015.

TACHIZAWA, T. Gestão ambiental e responsabilidade social corporativa. 7ª . ed. São Paulo: Atlas, 2011.

TACHIZAWA, T.; ANDRADE, R. Gestão socioambiental: estratégias na nova era da sustentabilidade. 2a․ ed. Rio de Janeiro: Elsevier, 2011.

VASCONCELOS, Y. L. Estudos Bibliométricos: Procedimentos Metodológicos e Contribuições. Revista UNOPAR Cient., Ciênc. Juríd. Empres .Londrina, v. 15, n. 2, p. 211-220, 2014.

VERGARA, S. C. Projeto e relatório de pesquisa em administração. 11. ed. São Paulo: Atlas, 2009.

VIEIRA, A. M.; RIVERA, D. P. B. A Hermenêutica no Campo Organizacional: duas possibilidades interpretativistas de pesquisa. Revista Brasileira de Gestão de Negócios, v. 14, n. 44, p. 261-273, 2012.

WORLD BUSINESS COUNCIL FOR SUSTAINABLE DEVELOPMENT (WBCSD). CSR: meeting changing expectations. 2002. Disponível em: http://old.wbcsd.org/work-program/business-role/ previous-work/corporate-social-responsibility.aspx. Acesso em: 28 jan. 2016.

ZYLBERSZTAIN, D.; LINS, C. Sustentabilidade e Geração de valor: a transição para o século XXI. Rio de Janeiro: Elsevier, 2010.

Recebido em: 4-10-2017

Aprovado em: 21-12-2020

Avaliado pelo sistema double blind review.

Disponível em http://mjs.metodista.br/index.php/roc 